\title{
CD36 gene polymorphism rs1761667 (G > $A$ ) is associated with hypertension and coronary artery disease in an Iranian population
}

\author{
Mohammad Amin Momeni-Moghaddam ${ }^{1,2}$, Gholamreza Asadikaram², ${ }^{*}$ (D, Hamed Akbari, ${ }^{2,3}$, Moslem Abolhassani ${ }^{2}$,
} Mohammad Masoumi ${ }^{4}$, Zahra Nadimy ${ }^{4}$ and Mohammad Khaksari ${ }^{5}$

\begin{abstract}
Background: CD36 is associated with regulation of lipid metabolism, atherosclerosis, and blood pressure. Moreover, its variation may be involved in the development of hypertension and/or coronary artery disease (CAD). The present study was conducted to investigate the possible association of CD36 rs1761667 (G > A) polymorphism with hypertension and/or CAD in the southeastern of Iran.

Methods: The present observational study was composed of 238 subjects who were admitted for coronary angiography, and divided into four groups: 1) hypertensive without CAD (H-Tens, $n=52)$; 2 ) hypertensive with CAD (CAD + H-Tens, $n=57)$; 3) CAD without hypertension (CAD, $n=65)$; and 4) non-hypertensive without CAD as the control group (Ctrl, $n=64)$. The CD36 rs 1761667 polymorphism was genotyped with PCR-RFLP method. Association between CD36 rs1761667 genotypes and the risk of CAD and hypertension was assessed using multinomial regression by adjusting for age, sex, creatinine, fasting blood sugar (FBS), systolic blood pressure (SBP) and diastolic blood pressure (DBP).

Results: In the present study, minor allele (A) frequency was 0.36. The genotype, but not allele frequency of the CD36 rs 1761667 was significantly different between the four study groups $(p=0.003)$. Furthermore, using a recessive inheritance model CD36 rs 1761667 polymorphism was significantly associated with an increased risk of CAD with hypertension $(\mathrm{OR}=5.677 ; 95 \% \mathrm{Cl}=1.053-30.601 ; p=0.043)$. However, using the dominant model of CD36 rs 1761667 had a protective effect on $\mathrm{H}$-Tens and CAD patients.

Conclusion: The present findings revealed an association between CD36 rs1761667 polymorphism and susceptibility to hypertension and/or CAD in a southeastern Iranian population.
\end{abstract}

Keywords: CD36, Coronary artery disease, Hypertension, Polymorphism, SNP

\section{Background}

Cardiovascular disease (CVD) is one of the most important threats to human life around the world, and includes subcategories such as coronary artery disease (CAD), acute coronary syndrome (ACS) and ischemic cardiomyopathy [1]. CAD is a multifactorial disorder which develops and progresses as a result of both environmental and genetic

\footnotetext{
* Correspondence: Gh_asadi@kmu.ac.ir; asadi_ka@yahoo.com

${ }^{2}$ Department of Biochemistry, School of Medicine, Kerman University of Medical Sciences, Kerman, Iran

${ }^{3}$ Endocrinology and Metabolism Research Center, Institute of Basic and Clinical Physiology Sciences, Kerman, Iran

Full list of author information is available at the end of the article
}

factors [2]. Various risk factors are involved in the development of CAD, including, atherosclerosis, hypertension, smoking, lifestyle, high fat diet, non-exercise and diabetes mellitus (DM) [1, 3-7].

CD36, a transmembrane glycoprotein, is a member of class B scavenger receptor family. In addition to monocytes and macrophages, it is expressed in a number of other cells, such as adipocytes, endothelial cells, and platelets. Multiple ligands are attached to this receptor and CD36 participates in many biological processes [8].

Recently, various studies have revealed results about the relationship between CD36 gene polymorphisms and

(c) The Author(s). 2019 Open Access This article is distributed under the terms of the Creative Commons Attribution 4.0 International License (http://creativecommons.org/licenses/by/4.0/), which permits unrestricted use, distribution, and reproduction in any medium, provided you give appropriate credit to the original author(s) and the source, provide a link to the Creative Commons license, and indicate if changes were made. The Creative Commons Public Domain Dedication waiver (http://creativecommons.org/publicdomain/zero/1.0/) applies to the data made available in this article, unless otherwise stated. 
obesity on the one hand and CD36 gene polymorphisms, hypertension, and CVDs on the other. The CD36 gene with $32 \mathrm{~kb}$ is located on the chromosome 7 (q11.2) and contains 15 exons [9]. SNP rs1761667 (G>A) is located in intron of 5' flanking exon 1A [10]. The CD36 receptor has high-affinity for long chain fatty acids (FAs) and is involved in metabolism of lipids. The A allele of rs1761667 decreases the CD36 expression and is related with upper recognition taste thresholds for fat (i.e., lower oral sensitivity to fat) [11]. Moreover, clinical investigations have shown that polymorphisms of this gene (such as rs1761667, rs10499859, rs3173798 and rs1049673) can influence the lipid metabolism, cardiovascular risk, essential hypertension, insulin resistance, familial type 2 diabetes mellitus (T2DM) and body mass index (BMI) [12-14]. For example, this receptor has high-affinity for long chain fatty acids (FAs) and is involved in lipid metabolism.

It is believed that CD36 polymorphisms confer susceptibility for hypertension and/or CAD due to the roles of CD36 in the regulation of lipid metabolism, atherosclerosis, and blood pressure [12, 15, 16].

Therefore, the present study was conducted aiming to evaluate the CD36 rs1761667 polymorphism in patients with CAD and hypertension in a southeastern Iranian population.

\section{Methods}

\section{Study subjects}

This observational study was performed on a total of 238 individuals who were admitted for coronary angiography to Shafa Hospital of Kerman University of Medical Sciences, Kerman, Iran (from July 2014 to December 2015). Subject selection process was conducted as described elsewhere [17-19]. Briefly, all CAD-suspected participants were examined by coronary angiography, before which they went through CAD treatment as they were symptomatic, had a history of hospitalization in coronary care unit (CCU), or there was evidence of myocardial ischemia in noninvasive investigations such as an exercise test or perfusion imaging. The inclusion criteria were as follows: participants' consent, subjects with symptoms of the ischemic heart disease and those diagnosed with CAD by coronary angiography. Subjects suffering from cancer, chronic kidney, respiratory and autoimmune diseases, congenital heart disease, and stroke were excluded [17]. The subjects were divided into four groups: 1) hypertensive without CAD (H-Tens, $n=52)$; 2) hypertensive with CAD (CAD + H-Tens, $n=57)$; 3) CAD without hypertension (CAD, $n=65)$; and 4) non-hypertensive without CAD as the control group (Ctrl, $n=64$ ) (Fig. 1).

This study conforms to the Declaration of Helsinki regarding research involving human subjects and was approved by the Ethics Committee of Kerman University of Medical Sciences, Kerman, Iran (IR.KMU.REC.1395.261).

\section{Samples and data collection}

Interviews were conducted to gather demographic data from all participants, each of whom provided an approximate amount of $10 \mathrm{ml}$ of blood, of which $5 \mathrm{ml}$ was collected into vacutainer tubes containing EDTA

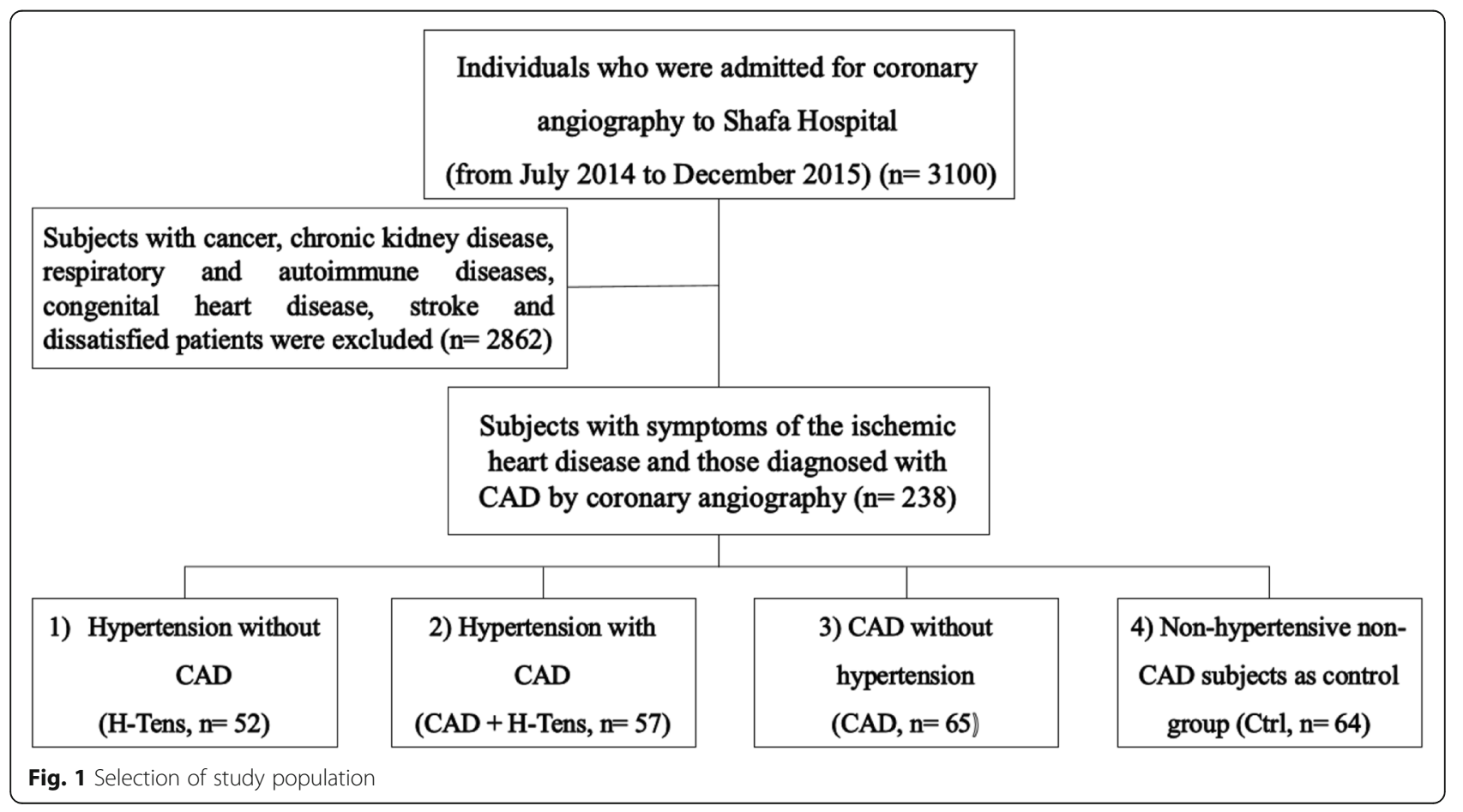


(for DNA extraction) and $5 \mathrm{ml}$ into vacutainer tubes without anti-coagulation agent. The samples were stored at room temperature and then centrifuged for serum separation. The serum samples were aliquoted and frozen at $-20^{\circ} \mathrm{C}$ to be used for subsequent experiments. Fasting blood sugar (FBS), total cholesterol (TC), triglycerides (TG), high-density lipoprotein cholesterol (HDL-C), low-density lipoprotein cholesterol (LDL-C), sodium $(\mathrm{Na})$, potassium $(\mathrm{K})$, creatinine $(\mathrm{Cr})$, and urea were determined using commercially available kits (Pars Azmoon, Tehran, Iran). BMI was calculated as weight divided by the square of height $\left(\mathrm{kg} / \mathrm{m}^{2}\right)$. Blood pressure was also measured from the right arm using an automatic sphygmomanometer during supine rest with 10-min intervals, and an average number of three blood pressure measurements were used. The criteria for occurrence of hypertension were as follow: a systolic blood pressure $(\mathrm{SBP}) \geq 140 \mathrm{mmHg}$, a diastolic blood pressure (DBP) $\geq 90$ $\mathrm{mmHg}$ and receiving antihypertensive medication.

\section{Genotyping}

Genomic DNA was extracted from white blood cells using the salting out method [20].

The concentration of extracted DNA was measured using Nanodrop spectrophotometer (ND-1000, ThermoFisher Scientific, Wilmington, USA). It was then frozen at $-70{ }^{\circ} \mathrm{C}$ to be used for subsequent experiments. Genotypes of CD36-rs1761667 polymorphism were determined using the polymerase chain reaction-restriction fragment length polymorphism (PCR-RFLP) method as described below.

The SNP was detected by PCR using following primers: 5'- CAAGGTCTGGTATCCACCTGTT - 3' (forward), 5' - ATGAAGCTTCCCGCCTTAGAA - 3' (reverse) and amplification was carried out using a Biometra $\mathrm{T}$ advanced (Analytik Jena, Germany). PCR conditions were as follows: initial denaturation at $95{ }^{\circ} \mathrm{C}$ for $5 \mathrm{~min}$, followed by 35 cycles of amplification including denaturation at $95^{\circ} \mathrm{C}$, annealing at $60^{\circ} \mathrm{C}$, extension at $72^{\circ} \mathrm{C}$ (each comprising $30 \mathrm{~s}$ ), and the final extension at $72^{\circ} \mathrm{C}$ for $5 \mathrm{~min}$. PCR products $(10 \mu \mathrm{l})$ were digested with $\mathrm{HhaI}$ restriction endonuclease (Thermo Scientific, USA) at $37^{\circ} \mathrm{C}$ for $16 \mathrm{~h}$ and fragments were separated by agarose gel electrophoresis $(1.5 \%$ agarose) stained with ethidium bromide. Afterwards, being observed by ultraviolet light (UV Tec Cambridge Gel doc), three genotypes of CD36-rs1761667 were detected which include: GG (161 and $264 \mathrm{bp}), \mathrm{GA}(161,245$, and $425 \mathrm{bp})$, and AA (425 bp).

\section{Statistical analysis}

All continuous and categorical variables were expressed, respectively, in the form of mean \pm standard deviation $(\mathrm{M} \pm \mathrm{SD})$ and counts (percentages). The differences among groups were assessed using one-way analysis of variance (ANOVA)/Kruskal-Wallis with post-hoc Tukey/ Mann-Whitney U-tests as well as Chi-square/Fisher's exact tests. Deviation from the Hardy-Weinberg equilibrium (HWE) was tested by the Chi-square test. To examine the independent roles that the genotypes play against hypertension and CAD risk, multinomial logistic regression was carried out. The statistical analyses were performed using SPSS software version 23.0 for Windows (SPSS Inc., Chicago, IL). The $p$ values less than 0.05 were considered to be statistically significant. Raw $p$-values are reported and no correction for multiple testing was applied. Power analysis was performed using the Power and Sample Size Calculation $G^{*}$ Power software (version 3.1.9.2). In the post hoc power analysis, 1-beta (power) computed as a function of alpha ( $p$-value) and the sample size(s) used in the study. The significant level was considered as 0.05 .

\section{Results}

\section{Demographics analysis}

Demographic and biochemical parameters of all participants are presented in Table 1. There were significant differences in sex, Cr, SBP and DBP between the four groups $(p<0.001, p=0.012, p=0.002$, and $p=0.017$, respectively). However, with regard to other factors, no significant difference was found between the four study groups. In order to eliminate the effects of confounders such as age and sex, as well as adjusting for the baseline values of the desired variables (FBS, Cr, blood pressure, and etc.), these variables were included in regression model.

\section{Genotype and allele frequency distribution of CD36 rs1761667}

Genotype and allele frequency distributions of CD36 rs1761667 among the study groups are provided in Table 2. At the CD36 rs1761667, significant difference was found in genotype frequency between the four groups $(p=0.003)$. Additionally, regarding the genotype frequency of CD36 rs1761667, significant differences were observed between $\mathrm{H}$-Tens and Ctrl groups $(p=0.001)$. Likewise, the CAD $+\mathrm{H}$-Tens group showed a significant difference in the genotype distribution compared with $\mathrm{H}$ Tens patients and Ctrl groups $(p=0.029$ and $p=0.034$, respectively). Moreover, $\mathrm{H}-\mathrm{Tens}$ patients were shown to have a significantly lower A allele frequency compared to $\mathrm{CAD}+\mathrm{H}-\mathrm{Tens}$ and Ctrl subjects $(p=0.050$ and $p=0.045$, respectively). However, there were no significant differences regarding alleles between the other groups $(p>0.05$ for all comparisons). The genotypic frequencies in control group were in accordance with HWE and other groups were not in equilibrium $(P=0.005)$ (Table 2$)$. 
Table 1 Demographics and biochemical parameters of subjects among four groups

\begin{tabular}{|c|c|c|c|c|c|}
\hline Variables & H-Tens $(N=52)$ & CAD $+\mathrm{H}$-Tens $(N=57)$ & CAD $(N=65)$ & $\operatorname{Ctrl}(N=64)$ & $P$-value \\
\hline Age, years & $54.69 \pm 9.05$ & $56.52 \pm 11.00$ & $56.20 \pm 9.78$ & $54.00 \pm 10.40$ & 0.424 \\
\hline $\operatorname{Sex}(m / f)$ & $27 / 25$ & $44 / 13$ & $54 / 11$ & $39 / 26$ & $<0.001^{\mathrm{b}}$ \\
\hline BMI $\left(\mathrm{kg} / \mathrm{m}^{2}\right)$ & $27.02 \pm 5.48$ & $24.92 \pm 4.48$ & $24.52 \pm 4.37$ & $25.08 \pm 5.12$ & $0.057^{c}$ \\
\hline $\mathrm{FBS}(\mathrm{mg} / \mathrm{dl})$ & $94.23 \pm 12.68$ & $95.30 \pm 18.95$ & $94.30 \pm 15.13$ & $95.56 \pm 14.58$ & $0.860^{c}$ \\
\hline $\mathrm{TG}(\mathrm{mg} / \mathrm{dl})$ & $116.35 \pm 58.33$ & $109.57 \pm 56.25$ & $111.90 \pm 58.06$ & $107.92 \pm 37.93$ & $0.788^{c}$ \\
\hline $\mathrm{TC}(\mathrm{mg} / \mathrm{dl})$ & $143.13 \pm 32.82$ & $136.38 \pm 34.17$ & $144.03 \pm 38.52$ & $149.05 \pm 45.97$ & $0.492^{c}$ \\
\hline $\mathrm{HDL}-\mathrm{c}(\mathrm{mg} / \mathrm{dl})$ & $38.21 \pm 9.72$ & $37.11 \pm 9.62$ & $38.92 \pm 10.70$ & $41.63 \pm 10.32$ & $0.061^{\mathrm{a}}$ \\
\hline LDL-c (mg/dl) & $79.84 \pm 30.91$ & $77.46 \pm 27.65$ & $83.01 \pm 31.80$ & $83.43 \pm 41.38$ & $0.938^{c}$ \\
\hline $\mathrm{Na}(\mathrm{mmol} / \mathrm{l})$ & $139.60 \pm 3.23$ & $139.27 \pm 3.13$ & $139.70 \pm 2.95$ & $139.18 \pm 2.99$ & $0.702^{c}$ \\
\hline $\mathrm{K}(\mathrm{mmol} / \mathrm{l})$ & $4.34 \pm 0.44$ & $4.20 \pm 0.36$ & $4.34 \pm 0.43$ & $4.31 \pm 0.44$ & $0.311^{c}$ \\
\hline $\mathrm{Cr}(\mathrm{mg} / \mathrm{dl})$ & $0.98 \pm 0.22$ & $1.07 \pm 0.20$ & $1.10 \pm 0.19$ & $1.04 \pm 0.23$ & $0.012^{c}$ \\
\hline Urea (mg/dl) & $35.48 \pm 10.36$ & $35.39 \pm 9.10$ & $36.28 \pm 10.24$ & $34.76 \pm 12.67$ & $0.753^{c}$ \\
\hline $\mathrm{DBP}(\mathrm{mmHg})$ & $74.54 \pm 9.32$ & $72.73 \pm 12.06$ & $70.08 \pm 8.03$ & $75.73 \pm 8.28$ & $0.017^{c}$ \\
\hline $\mathrm{SBP}(\mathrm{mmHg})$ & $123.02 \pm 14.58$ & $121.25 \pm 13.25$ & $115.33 \pm 11.61$ & $122.14 \pm 14.21$ & $0.002^{c}$ \\
\hline
\end{tabular}

H-Tens Hypertension, CAD + H-Tens Coronary Artery Disease and Hypertension, CAD Coronary Artery Disease, Ctrl Control; BMI Body mass index, FBS Fasting blood sugar, TC Total cholesterol, TG Triglycerides, HDL-c High-density lipoprotein cholesterol, $L D L$ Low-density lipoprotein cholesterol, Na Sodium, $K$ potassium, $C r$ Creatinine, SBP Systolic Blood Pressure, DBP Diastolic Blood Pressure. Continuous and categorical values are presented as mean \pm SD and number, respectively ${ }^{a}$ ANOVA followed by post-hoc Tukey test

${ }^{\mathrm{b}}$ chi-square test

${ }^{\mathrm{C}}$ Kruskal-Wallis followed by post-hoc Mann-Whitney U-test

Table 3 depicts the comparison of demographic and laboratory parameters between the CD36 rs1761667 genotype groups among $\mathrm{H}-\mathrm{Tens}, \mathrm{CAD}+\mathrm{H}-\mathrm{Tens}$, CAD and Ctrl individuals. CAD + H-Tens patients with GG (145.06 \pm 80.98) genotypes showed significantly higher levels of TG compared to both GA $(94.24 \pm 32.39)$ and AA $(91.50 \pm$ 24.74) genotypes $(p=0.018)$. Furthermore, significantly lower levels of $\mathrm{Na}$ and $\mathrm{K}$ were found in GG genotype of CD36 rs1761667 between CAD patients as compared to GA $(p=0.029$ and $p=0.002$, respectively). However, regarding demographic and laboratory factors, no significant differences were observed between CD36 rs1761667 genotypes in Ctrl subjects ( $p>0.05$ for all comparisons).

\section{Results of multinomial regression models}

Results obtained from the multinomial regression model are presented in Table 4. Multinomial regression analysis was applied by adjusting for age and sex, Cr, FBS, SBP and DBP. Recessive genetic model of CD36 rs1761667 polymorphism was significantly associated with an increased risk of CAD + H-Tens $(\mathrm{OR}=5.677 ; 95 \% \mathrm{CI}=1.053-30.601 ; p=0.043)$. However, the dominant inheritance model $((\mathrm{GA}+\mathrm{AA})$ vs. (GG)) of CD36 rs1761667 demonstrated a protective effect among $\mathrm{H}-\mathrm{Tens}$ and $\mathrm{CAD}$ patients $(\mathrm{OR}=0.170$; $95 \% \mathrm{CI}=0.061-0.473 ; p=0.001, \mathrm{OR}=0.218 ; 95 \% \mathrm{CI}=$ $0.085-0.557 ; p=0.001)$.

Table 2 Genotype and allele frequencies of CD36 rs1761667 in the four study groups

\begin{tabular}{|c|c|c|c|c|c|c|c|c|c|c|c|}
\hline \multirow[t]{2}{*}{ SNP } & \multirow{2}{*}{$\begin{array}{l}\text { (1) H-Tens } \\
(N=52)\end{array}$} & \multirow{2}{*}{$\begin{array}{l}\text { (2) CAD + H-Tens } \\
(N=57)\end{array}$} & \multirow{2}{*}{$\begin{array}{l}\text { (3) CAD } \\
(N=65)\end{array}$} & \multirow{2}{*}{$\begin{array}{l}(4) C t r l \\
(N=64)\end{array}$} & \multicolumn{7}{|l|}{$P$-value } \\
\hline & & & & & 1 vs. 2 & 1 vs. 3 & 1 vs. 4 & 2 vs. 3 & 2 vs. 4 & 3 vs. 4 & $1 \& 2 \& 3 \& 4^{\epsilon}$ \\
\hline \multicolumn{12}{|l|}{ rs1761667 } \\
\hline $\mathrm{GG}$ & $6(0.12)$ & $17(0.30)$ & $12(0.18)$ & $26(0.4)$ & 0.029 & 0.563 & 0.001 & 0.103 & 0.034 & 0.016 & 0.003 \\
\hline GA & $40(0.77)$ & $38(0.67)$ & $45(0.7)$ & $30(0.46)$ & & & & & & & \\
\hline AA & $6(0.12)$ & $2(0.03)$ & $8(0.12)$ & $9(0.14)$ & & & & & & & \\
\hline Allele G & $52(0.5)$ & $72(0.63)$ & $69(0.53)$ & $82(0.63)$ & 0.050 & 0.640 & 0.045 & 0.112 & 0.990 & 0.102 & 0.086 \\
\hline Allele A & $52(0.5)$ & $42(0.37)$ & $61(0.47)$ & $48(0.37)$ & & & & & & & \\
\hline \multirow[t]{2}{*}{ HWE } & 0.0001 & 0.001 & 0.001 & 0.941 & & & & & & & \\
\hline & 15.076 & 10.664 & 9.880 & 0.005 & & & & & & & \\
\hline
\end{tabular}

(1) H-Tens Hypertension, (2) CAD + H-Tens Coronary Artery Disease and Hypertension, (3) CAD Coronary Artery Disease, (4) Ctrl Control, HWE Hardy-Weinberg Equilibrium. Data are presented as number (\%).The differences of CD36 rs 1,761,667 genotype and allele frequencies between study groups were analyzed using Chi-square/Fisher's exact tests

$\epsilon_{\text {significant difference between the four groups }(p<0.05)}$ 


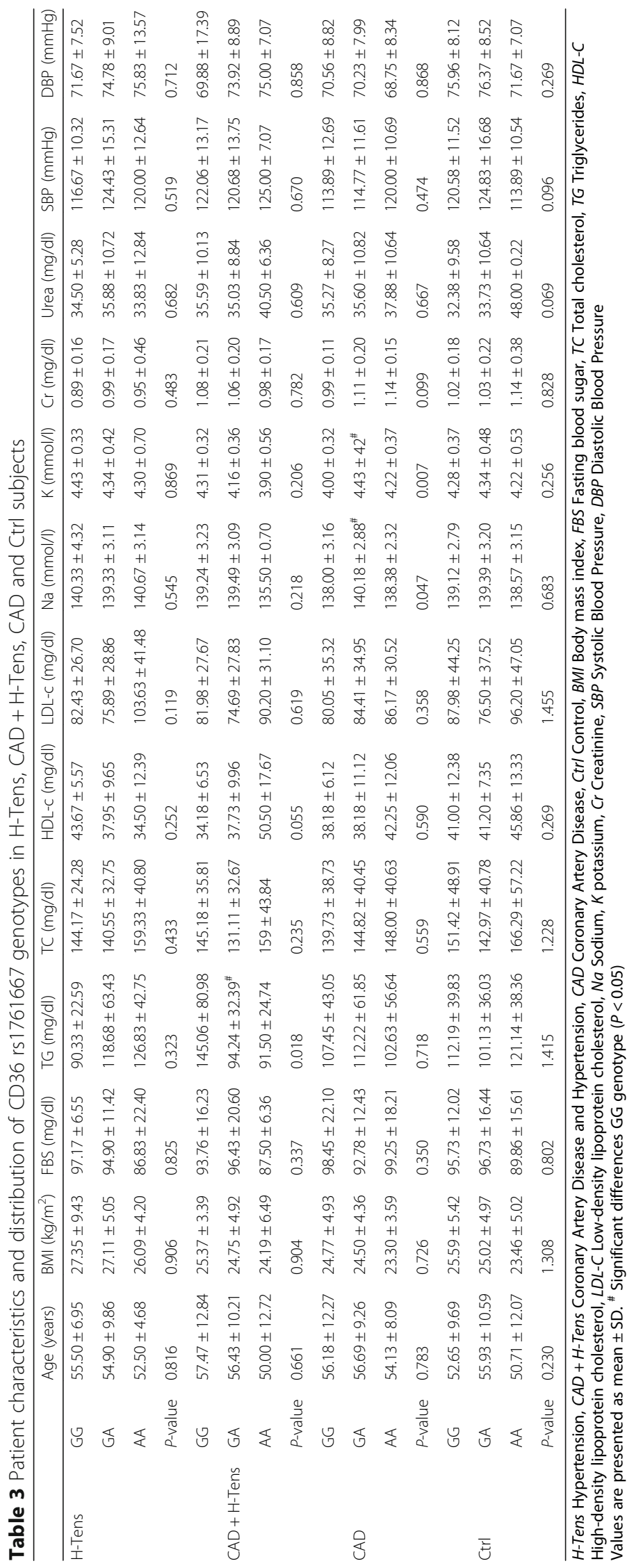


Table 4 Association between CD36 rs1761667 genotypes and the risk of CAD and hypertension with multinomial regression

\begin{tabular}{|c|c|c|c|c|c|c|}
\hline \multirow{2}{*}{$\begin{array}{l}\text { Mode of } \\
\text { inheritance }\end{array}$} & \multicolumn{2}{|c|}{ H-Tens vs. Ctrl } & \multicolumn{2}{|c|}{$\mathrm{CAD}+\mathrm{H}$-Tens vs. Ctrl } & \multicolumn{2}{|c|}{ CAD vs. Ctrl } \\
\hline & $P$-value & Adjusted OR [95\% Cl] & $P$-value & Adjusted OR [95\% Cl] & $P$-value & Adjusted OR [95\% Cl] \\
\hline \multicolumn{7}{|l|}{ Autosomal recessive } \\
\hline$(A A)$ vs. $(G G+G A)$ & 0.509 & $1.526[0.436-5.347]$ & $0.043^{*}$ & $5.677[1.053-30.601]$ & 0.342 & $1.793[0.538-5.979]$ \\
\hline \multicolumn{7}{|l|}{ Autosomal dominant } \\
\hline$(G A+A A)$ vs. $(G G)$ & $0.001 *$ & $0.170[0.061-0.473]$ & 0.097 & $0.502[0.223-1.132]$ & $0.001 *$ & $0.218[0.085-0.557]$ \\
\hline
\end{tabular}

H-Tens Hypertension, CAD + H-Tens Coronary Artery Disease and Hypertension, CAD Coronary Artery Disease, Ctrl Control

Adjusted for age, sex, $\mathrm{Cr}$, FBS, SBP and DBP using the multinomial regression model. OR, odds ratio; $\mathrm{Cl}, 95 \%$ confidence interval for the OR

*Significant differences $(p<0.05)$

According to power calculations, the sample size provided a $94 \%$ power $(p=0.05)$.

\section{Discussion}

Different studies on CD36 have shown that this receptor plays a key role in a number of disorders such as CVD, hypertension, and metabolic syndrome [8]. Many studies have been conducted on CD36 rs1761667 in CVD [12, 13, 16, 21], T2DM [22], metabolic syndrome [23] and obese groups [24, 25]. These studies have been carried out on different populations and in different parts of the world and the results are conflicting and the studies were small (Table 5). To the best of the authors' knowledge, no research has been performed on subjects with CAD and hypertension on an Iranian population. Therefore, the present study assessed the association of CD36 rs1761667 gene polymorphism with susceptibility to CAD and/ or hypertension on an Iranian southeastern population. Findings revealed that the A allele might be associated with hypertension and CAD.

The crucial role that CD36 plays in hypertension has been revealed by molecular studies [15]. Expressed in renal cells such as capillary endothelium, CD36 activates the endothelial nitric oxide synthase (eNOS) via fatty acids, thereby contributing to production of nitric oxide (NO). Decreased NO activity in renal medulla is found to be associated with hypertension [26], suggesting that reduced CD36 in renal cells may be associated with hypertension [15]. In contrast to the present findings, the study carried out by Solakivi et al. on 736 Finnish subjects suffering from hypertension did not show any association between CD36 rs1761667 gene polymorphism and hypertension [27]. However, the current results showed an increased risk of hypertension in recessive inheritance model, whereas A allele carriers of rs1761667 SNP demonstrated a protective effect on hypertension. The difference between the results obtained in the present

Table 5 CD36 rs1761667-related studies

\begin{tabular}{|c|c|c|c|c|c|c|c|c|c|}
\hline \multirow{2}{*}{$\begin{array}{l}\text { Ethnicity of the } \\
\text { population }\end{array}$} & \multicolumn{2}{|c|}{ Sample sizes } & \multirow[t]{2}{*}{ Clinical condition } & \multirow{2}{*}{$\begin{array}{l}\text { minor } \\
\text { allele }\end{array}$} & \multirow[t]{2}{*}{ MAF } & \multirow[t]{2}{*}{$P$-value } & \multirow[t]{2}{*}{ association results } & \multirow[t]{2}{*}{$P$-valuae } & \multirow[t]{2}{*}{ Ref. } \\
\hline & case & $\overline{\text { control }}$ & & & & & & & \\
\hline Mexican & 309 & 132 & overweight and obese & G & 0.4 & 0.06 & $\begin{array}{l}\text { high serum cholesterol levels were associated } \\
\text { with the AA genotype }\end{array}$ & 0.005 & {$[24]$} \\
\hline Indian & 250 & 150 & T2DM & A & 0.36 & 0.24 & A allele is significantly associated with T2DM & $<0.005$ & [22] \\
\hline Egyptian & 100 & 100 & MetS & G & 0.25 & 0.00 & $\begin{array}{l}\text { Subjects with } A G \text { and } G G \text { genotypes had } \\
\text { significantly higher systolic blood pressure, } \\
\text { wider waist circumstance, and higher degree } \\
\text { of dyslipidemia }\end{array}$ & $<0.001$ & [23] \\
\hline Algerian & 57 & 59 & $\begin{array}{l}\text { Obese and lean } \\
\text { children }\end{array}$ & A & 0.47 & 0.036 & A allele was higher in obese subjects & 0.03 & [25] \\
\hline $\begin{array}{l}\text { Chongqing Han } \\
\text { population of China }\end{array}$ & 112 & 129 & $\mathrm{CHD}$ & A & 0.31 & 0.480 & $\begin{array}{l}\text { Significantly higher frequency of the AG } \\
\text { genotype in the CHD group compared to } \\
\text { the control group. The plasma levels of } \\
\text { ox-LDL in CHD patients with AG genotype } \\
\text { were significantly higher }\end{array}$ & $\begin{array}{l}0.011 \\
0.010\end{array}$ & [13] \\
\hline Chinese Han & 374 & 1013 & $\begin{array}{l}\text { atherothrombotic } \\
\text { stroke }\end{array}$ & A & 0.35 & 0.113 & $\begin{array}{l}\text { A allele were associated with atherothrombotic } \\
\text { stroke in Chinese Han }\end{array}$ & 0.020 & [21] \\
\hline Egyptian & 71 & 76 & $C A D$ & $A$ & 0.46 & 0.680 & $\begin{array}{l}\text { The AG genotype involved in CAD pathogenesis } \\
\text { as well as increased BMI, T2DM and MetS }\end{array}$ & 0.001 & [12] \\
\hline Chinese Han & 215 & 252 & carotid atherosclerotic & A & 0.33 & 0.135 & $\begin{array}{l}\text { GA genotypes increase the susceptibility of } \\
\text { females to carotid atherosclerosis }\end{array}$ & 0.041 & [16] \\
\hline
\end{tabular}


study and those of the former ones was most likely due to the racial-ethnic discrepancies and several other differences such as sample size.

Numerous studies have emphasized the role of CD36 in macrophage as a mediator of taking-up ox-LDL, so it has a special role in developing atherosclerotic plaque and CAD [28]. A previous study by Banerjee et al. evaluated the CD36 rs1761667 gene polymorphism, showing that this SNP is associated with T2DM [22]. Boghdady et al. showed that the AG genotype of the CD36 rs1761667 SNP may play a part in CAD pathogenesis and increase BMI, T2DM and metabolic syndrome in the Egyptian Sohag population [12]. Moreover, Zhang et al. obtained similar results in a study on patients with CHD from a Chinese population [13]. Contrary to the previous studies, our CAD subjects as well as those with a combination of CAD and hypertension showed a lower risk in A allele carriers of CD36 rs1761667 SNP. The reason for the differences reported in these findings as well as other studies may be the interactions of rs1761667 polymorphism with other variants in CD36 gene, ethnicity of the population, patients' gender, sample size, differences in the genetic constitution and nongenetic or environmental properties, genetic heterogeneity, gene-environment and gene-gene interactions in various populations.

The present results showed that the A allele frequency of CD36 rs1761667 gene polymorphism was $0.37 \%$ in the Ctrl group which was similar to a study on healthy Egyptian subjects $(0.46 \%)$ [12] and healthy Chinese ones $(0.32 \%)$ [13]. It can be noted that diversity of ethnicity does not interfere the distribution of A allele CD36 frequency.

It has been demonstrated that CD36 binds to fatty acids and is involved in the lipid metabolism [29]. Genotypes of rs1761667 as well as the traditional risk factors of CAD such as age, sex, BMI and lipid profile were all taken into account. According to previous investigations, regarding TG, no significant difference was found between the CHD and CAD patients with different rs1761667 genotypes [12,13]. Likewise, another study conducted by Ramos-Arellano et al. demonstrated that in a group of 232 Mexican youths with normal-weight, there was no significant difference between levels of TC, TG, and LDL-C in different genotypes of the CD36 rs1761667 polymorphism [30]. However, Bayoumy et al. revealed that subjects with metabolic syndrome had a significantly higher degree of dyslipidemia in GG and AG genotypes of CD36 rs1761667 than patients with AA genotype [23]. The only significant increase was observed in TG in the CAD + H-Tens group in GG genotype. It is hypothesized that the variety of medications used and duration of the drugs' consumption may be the possible causes of these discrepancies.
It is noteworthy that even though the role of CD36 in multiple diseases has been revealed, it is the first study which sought to examine the genetic variation of CD36 in association with CAD and/or hypertension susceptibility.

A number of limitations should be considered when interpreting the current results which included the fact that it was difficult and time-consuming to select the $\mathrm{H}$ Tens group, and hypertensive subjects without any critical coronary vessel stenosis. That is, one of the significant restrictions of the study included selection of non-CAD hypertensive patients as all the CAD hypertensive ones were subjected to coronary angiography, thus presenting a challenging and difficult task to choose hypertensive patients without any critical coronary vessel stenosis. Therefore, the sample size in this study is small. Moreover, the population of the study was restricted to southeastern Iran and, additionally, the study was a hospital-based observational study, as a result of which the findings could not be generalized to other racial/ethnic groups in other parts of the globe. Although diastolic blood pressure was higher in the control group compared to the hypertensive group, this difference was not statistically significant. Furthermore, the findings were adjusted using multinomial regression model to account for cofounders and no correction for multiple testing was done, moreover, only control genotypes were in HWE and one SNP was studied. In order to eliminate the effects of confounders such as age and sex, as well as adjusting for the baseline values of the desired variables (FBS, Cr, blood pressure, and etc.), these variables were included in regression model.

\section{Conclusion}

The present study presented the first evidence which suggests that CD36 rs1761667 gene polymorphism might be a factor predisposing to hypertension and CAD in a southeastern Iranian population. It should be noted that the results need confirmation in further, more conclusive, and prospective studies incorporating a wide range of ethnicities with a gene expression and functional assay in the future.

\footnotetext{
Abbreviations

ACS: Acute coronary syndrome; BMI: Body mass index; $\mathrm{CAD}+\mathrm{H}$ -

tens: coronary artery disease and hypertension; CAD: Coronary artery disease; CCU: Coronary care unit; CHD: Coronary heart disease; $\mathrm{Cr}$ : Creatinine;

Ctrl: Control; CVD: Cardiovascular disease; DBP: Diastolic blood pressure;

DM: Diabetes mellitus; eNOS: Endothelial nitric oxide synthase; FA: Fatty acid;

FBS: Fasting blood sugar; HDL-C: High-density lipoprotein cholesterol; $\mathrm{H}$ -

Tens: Hypertension; HWE: Hardy-Weinberg equilibrium; ICH: Intracerebral hemorrhage; K: Potassium; LDL: Low-density lipoprotein; LDL-C: Low-density lipoprotein cholesterol; Na: Sodium; NO: Nitric oxide; ox-LDL: Oxidized LDL; PCR: Polymerase chain reaction; PCR-RFLP: Polymerase chain reactionrestriction fragment length polymorphism; ROS: Reactive oxygen species; SBP: Systolic blood pressure; SNP: Single nucleotide polymorphism; T2DM: Type 2 diabetes mellitus; TC: Total cholesterol; TG: Triglycerides
} 


\section{Acknowledgements}

We would like to thank all the participants in our study. The authors thankfully acknowledge the support of the dissertation grant.

\section{Authors' contributions}

MAMM, GA, HA, MM, MA \& MK set up the study design and interpreted the data. MAMM, GA \& HA performed the statistical analyses, interpreted the data and drafted the manuscript. GA, HA \& MAMA revised the manuscript critically and provided continuous guidance throughout the study. MM, MA \& ZN collecting the data and do the experiments. All authors read and approved the final manuscript.

\section{Funding}

This work was supported by grants from Kerman University of Medical Sciences, Kerman, Iran (IR/KMU/95/212) and was a part of Ph.D. thesis.

\section{Availability of data and materials}

The dataset analyzed during the current study are available from the corresponding author on reasonable request.

\section{Ethics approval and consent to participate}

This study conforms to the Declaration of Helsinki regarding research involving human subjects and is approved by the ethics committee of Kerman University of Medical Sciences, Kerman, Iran (IR.KMU.REC.1395.261). All participants signed the written informed consents form.

\section{Consent for publication}

Not applicable.

\section{Competing interests}

The authors declare that they have no conflict of interests.

\section{Author details}

${ }^{1}$ Neuroscience Research Center, Institute of Neuropharmacology, Kerman University of Medical Sciences, Kerman, Iran. Department of Biochemistry, School of Medicine, Kerman University of Medical Sciences, Kerman, Iran. ${ }^{3}$ Endocrinology and Metabolism Research Center, Institute of Basic and Clinical Physiology Sciences, Kerman, Iran. ${ }^{4}$ Cardiovascular Research Center, Institute of Basic and Clinical Physiology Sciences, Kerman University of Medical Sciences, Kerman, Iran. ${ }^{5}$ Physiology Research Center, Institute of Neuropharmacology, Kerman University of Medical Sciences, Kerman, Iran.

\section{Received: 7 December 2018 Accepted: 20 May 2019}

\section{Published online: 11 June 2019}

\section{References}

1. Sanchis-Gomar F, Perez-Quilis C, Leischik R, Lucia A. Epidemiology of coronary heart disease and acute coronary syndrome. Ann Transl Med. 2016:4(13):256

2. Wang Y, Chen X-Y, Wang K, Li S, Zhang X-Y. Myeloperoxidase polymorphism and coronary artery disease risk: a meta-analysis. Medicine. 2017;96(27):e7280

3. Barbero U, D'Ascenzo F, Nijhoff F, Moretti C, Biondi-Zoccai G, Mennuni M, Capodanno D, Lococo M, Lipinski MJ, Gaita F. Assessing risk in patients with stable coronary disease: when should we intensify care and follow-up? Results from a meta-analysis of observational studies of the COURAGE and FAME era. Scientifica. 2016;2016:3769152.

4. Asadikaram G, Akbari H, Safi Z, Shadkam M, Khaksari M, Shahrokhi N, Najafipour H, Sanjari M, Arababadi MK. Downregulation of IL-22 can be considered as a risk factor for onset of type 2 diabetes. J Cell Biochem. 2018;119(11):9254-60.

5. Zengin E, Bickel C, Schnabel RB, Zeller T, Lackner K-J, Rupprecht H-J, Blankenberg S, Westermann D, Investigators CSAS. Risk factors of coronary artery disease in secondary prevention-results from the AtheroGene—study. PLoS One. 2015;10(7):e0131434

6. Eisen A, Bhatt DL, Steg PG, Eagle KA, Goto S, Guo J, Smith SC, Ohman EM, Scirica BM. Investigators RR: angina and future cardiovascular events in stable patients with coronary artery disease: insights from the reduction of Atherothrombosis for continued health (REACH) registry. J Am Heart Assoc. 2016;5(10):e004080.
7. Stevens SL, Wood S, Koshiaris C, Law K, Glasziou P, Stevens RJ, McManus RJ. Blood pressure variability and cardiovascular disease: systematic review and meta-analysis. bmj. 2016;354:i4098.

8. Gong Q-W, Liao M-F, Liu L, Xiong X-Y, Zhang Q, Zhong Q, Zhou K, Yang YR, Meng Z-Y, Gong C-X. CD36 gene polymorphisms are associated with intracerebral hemorrhage susceptibility in a Han Chinese population. Biomed Res Int. 2017;2017:5352071.

9. Yun YM, Song EY, Song SH, Song J, Kim JQ. CD36 polymorphism and its relationship with body mass index and coronary artery disease in a Korean population. Clin Chem Lab Med. 2007;45(10):1277-82.

10. Daoudi H, Plesník J, Sayed A, Šerý O, Rouabah A, Rouabah L, Khan NA. Oral fat sensing and CD36 gene polymorphism in Algerian lean and obese teenagers. Nutrients. 2015;7(11):9096-104.

11. Pepino MY, Kuda O, Samovski D, Abumrad NA. Structure-function of CD36 and importance of fatty acid signal transduction in fat metabolism. Annu Rev Nutr. 2014;34:281-303.

12. Boghdady A, Arafa UA, Sabet EA, Salama E, El Sharawy A, Elbadry MI. Association between rs1761667 polymorphism of CD36 gene and risk of coronary atherosclerosis in Egyptian population. Cardiovasc Diagn Ther. 2016;6(2):120

13. Zhang $Y$, Ling Z, Deng S, Du H, Yin Y, Yuan J, She Q, Chen Y. Associations between CD36 gene polymorphisms and susceptibility to coronary artery heart disease. Braz J Med Biol Res. 2014;47(10):895-903.

14. Che J, Shao Y, Li G. Association between rs1049673 polymorphism in CD36 and premature coronary heart disease. Genet Mol Res. 2014;13(7708):17.

15. Yokoi H, Yanagita M. Targeting the fatty acid transport protein CD36, a class B scavenger receptor, in the treatment of renal disease. Kidney Int. 2016; 89(4):740-2.

16. Chu Y, Lao W, Jin G, Dai D, Chen L, Kang H. Evaluation of the relationship between CD36 and MARCO single-nucleotide polymorphisms and susceptibility to carotid atherosclerosis in a Chinese Han population. Gene. 2017;633:66-70.

17. Akbari H, Asadikaram G, Jafari A, Nazari-Robati M, Ebrahimi G, Ebrahimi N, Masoumi M. Atorvastatin, losartan and captopril may upregulate IL-22 in hypertension and coronary artery disease; the role of gene polymorphism. Life Sci. 2018;207:525-31.

18. Nowzari Z, Masoumi M, Nazari-Robati M, Akbari H, Shahrokhi N, Asadikaram G. Association of Polymorphisms of leptin, leptin receptor and Apelin receptor genes with susceptibility to coronary artery disease and hypertension. Life Sci. 2018;207:166-71.

19. Akbari H, Asadikaram G, Aria H, Fooladi S, Vakili S, Masoumi M. Association of Klotho gene polymorphism with hypertension and coronary artery disease in an Iranian population. BMC Cardiovasc Disord. 2018;18(1):237

20. Saremi Mohammad A, Saremi M, Tavallaei M. Rapid genomic DNA extraction (RGDE). Forensic Sci Int. 2008;1(1):63-5.

21. Zhang Y, Zang J, Wang B, Li B, Yao X, Zhao H, Li W. CD36 genotype associated with ischemic stroke in Chinese Han. Int J Clin Exp Med. 2015; 8(9):16149.

22. Banerjee M, Gautam S, Saxena M, Bid HK, Agrawal C. Association of CD36 gene variants rs1761667 ( $G>$ a) and rs1527483 (C> T) with type 2 diabetes in north Indian population. Int J Diabetes Mellitus. 2010;2(3): 179-83.

23. Bayoumy NM, El-Shabrawi MM, Hassan $\mathrm{HH}$. Association of cluster of differentiation 36 gene variant rs1761667 (G> a) with metabolic syndrome in Egyptian adults. Saudi Med J. 2012:33(5):489-94.

24. Lopez-Ramos O, Panduro A, Martinez-Lopez E. Genetic variant in the CD36 gene (rs1761667) is associated with higher fat intake and high serum cholesterol among the population of West Mexico. J Nutr Food Sci. 2005:5:1-5

25. Sayed A, Šerý O, Plesnik J, Daoudi H, Rouabah A, Rouabah L, Khan N. CD36 AA genotype is associated with decreased lipid taste perception in young obese, but not lean, children. Int J Obes. 2015:39(6):920.

26. Pravenec M, Churchill PC, Churchill MC, Viklicky O, Kazdova L, Aitman TJ, Petretto $\mathrm{E}$, Hubner N, Wallace CA, Zimdahl H. Identification of renal Cd36 as a determinant of blood pressure and risk for hypertension. Nat Genet. 2008; 40(8):952-4

27. Solakivi T, Kunnas T, Nikkari ST. Contribution of fatty acid transporter (CD36) genetic variant rs1761667 to body mass index, the TAMRISK study. Scand J Clin Lab Invest. 2015;75(3):254-8.

28. Park YM. CD36, a scavenger receptor implicated in atherosclerosis. Exp Mol Med. 2014;46(6):e99. 
29. Goudriaan JR, Den Boer MA, Rensen PC, Febbraio M, Kuipers F, Romijn JA, Havekes LM, Voshol PJ. CD36 deficiency in mice impairs lipoprotein lipasemediated triglyceride clearance. J Lipid Res. 2005;46(10):2175-81.

30. Ramos-Arellano LE, Salgado-Bernabé AB, Guzmán-Guzmán IP, Salgado-

Goytia L, Muñoz-Valle JF, Parra-Rojas I. CD36 haplotypes are associated with lipid profile in normal-weight subjects. Lipids Health Dis. 2013;12(1):167-76.

\section{Publisher's Note}

Springer Nature remains neutral with regard to jurisdictional claims in published maps and institutional affiliations.

Ready to submit your research? Choose BMC and benefit from:

- fast, convenient online submission

- thorough peer review by experienced researchers in your field

- rapid publication on acceptance

- support for research data, including large and complex data types

- gold Open Access which fosters wider collaboration and increased citations

- maximum visibility for your research: over $100 \mathrm{M}$ website views per year

At $B M C$, research is always in progress.

Learn more biomedcentral.com/submissions 